\title{
Associated Biologic Entity
}

National Cancer Institute

\section{Source}

National Cancer Institute. Associated Biologic Entity. NCI Thesaurus. Code C93387.

An individual biologic entity connected/linked to a subject. 